\title{
Problemas ontológico-políticos de la copia reproductible: consideraciones sobre la crítica de Hennion y Latour a Benjamin
}

\author{
Agustín Berti y Diego Parente \\ Consejo Nacional de Investigaciones Científicas y Técnicas de Argentina
}

Resumen: El presente artículo indaga algunas implicaciones ontológicas y políticas del fenómeno de reproducción técnica tal como se presenta a inicios del siglo $\mathrm{XX}$. Hay cierto consenso básico en filosofia de la técnica sobre la idea de que las innovaciones sociales y politicas no pueden comprenderse independientemente de la emergencia y utilización de ciertos medios técnicos. Nuestro interés en este trabajo reside en explorar críticamente una faceta habitualmente subestimada en este tipo de indagación sobre la técnica: cómo las propiedades inherentemente técnicas atadas a ciertos nuevos sistemas técnicos (entre ellos, los sistemas de reproducción) favorecen fácticamente a algunos fines y, por tanto, tienden hacia una serie de utilizaciones en desmedro de otras. Con este objetivo en mente, el presente trabajo reconstruye la posición de Walter Benjamin sobre el problema de la copia reproductible y lo pone en diálogo con las criticas recientes de Hennion y Latour.

Palabras clave: copia; técnica moderna; reproductibilidad; Benjamin; Latour

\begin{abstract}
Ontological-political Problems of the Reproducible Copy: Considerations on Hennion and Latour's Critique of Benjamin". This paper explores some ontological and political implications of the phenomenon of technical reproduction that takes place at the beginning of the 20th century. In philosophy of technology there is a basic agreement that social and political innovations cannot be understood independently from the emergence and use of certain technical means. Our objective in this work is to critically explore an aspect usually underestimated in this type of inquiry about technology: how inherently technical properties attached to certain new technical systems (for instance, reproduction systems) can actually favor some purposes and uses instead of others. With this objective, the paper reconstructs Walter Benjamin's perspective on the problem of reproducible copies and discusses Latour and Hennion's recent criticisms.
\end{abstract}

Keywords: copy; modern technology; reproducibility; Benjamin; Latour 


\section{Introducción: Política y reproductibilidad}

¿Qué serie de vinculaciones existen entre los medios técnicos disponibles en una época y las distintas sociedades que los albergan? Por caso, ¿hay un hilo que conecta forzosamente el nacimiento del cine con los regímenes totalitarios? ¿Y qué tipo de conexión puede descubrirse entre estos dos fenómenos decididamente heterogéneos? A partir del siglo XIX y especialmente en el siglo $\mathrm{XX}$, la filosofia en sus diversas orientaciones (Heidegger, Mumford, Marcuse, Winner, entre otros) ha intentado responder coherentemente a estas preguntas dando lugar a imágenes distópicas y utópicas sobre el rol de la tecnología en la emancipación social.

Restringiendo históricamente el campo de indagación a la copia reproductible a escala industrial, el objetivo de este artículo es explorar cuáles son las implicaciones ontológicas y políticas que posee el fenómeno de reproducción técnica tal como se presenta a inicios del siglo XX para la filosofia de la técnica. Podríamos afirmar que hay cierto consenso básico sobre la idea de que las innovaciones sociales y politicas no pueden comprenderse independientemente de la emergencia y utilización de ciertos medios técnicos. Nuestro interés en este trabajo reside en explorar críticamente una faceta habitualmente subestimada en este tipo de indagación sobre la técnica: cómo las propiedades inherentemente técnicas atadas a ciertos nuevos sistemas técnicos (entre ellos, los sistemas de reproducción) favorecen fácticamente a algunos fines y, por tanto, tienden hacia una serie de utilizaciones en desmedro de otras. Por detrás de esta interpretación se halla la idea de que los impactos sociales y politicos de la tecnología no pueden comprenderse apropiadamente a partir del paradigma del uso de nuevos sistemas sino, más bien, concentrándonos en cómo ciertas propiedades inmanentes de los sistemas favorecen ciertos caminos de desarrollo técnico sin que ello implique aceptar una posición determinista.

Con este objetivo en mente, el presente trabajo está organizado de la siguiente manera: la primera sección se ocupa de introducir, tanto histórica como conceptualmente, el valor filosófico del problema de la copia reproducible. La segunda sección sitúa a Walter Benjamin en relación con la taxonomía ético-política ante la técnica propuesta por Feenberg. La tercera sección, por su parte, se ocupa de responder a las críticas de Hennion y Latour a Benjamin sustituyendo la tensión materialismo/idealismo por la tensión inmanentismo/ 
transcendentismo. El hilo que corre a través de estas tres secciones del trabajo es la pregunta por la figura de Benjamin qua filósofo de la técnica ${ }^{1}$.

\subsection{Copia y técnica: algunas aclaraciones preliminares}

A nuestro juicio, en el ámbito del pensamiento sobre la técnica, el problema de la copia ha recibido atención dispersa y aún no ha sido sistematizado. Una intuición que orienta este trabajo es que la replicabilidad de objetos y procesos está en la base de cualquier definición de técnica, desde las más primitivas, pasando por las artesanales, hasta llegar a las industriales. La centralidad de la idea de copia en la producción técnica es paradigmática, por ejemplo, en abordajes antropológicos como la obra de Leroi-Gourhan ${ }^{2}$, quien sostiene que los procesos de reproducción de ciertas formas técnicas responden a constricciones objetivas dadas por los materiales y las operaciones corporalmente realizables por humanos. En el caso de Leroi-Gourhan, la pregunta no solo atañe a la copia sino fundamentalmente a la estabilidad, la fiabilidad y la transculturalidad de ciertos procesos de reproducción de objetos técnicos. Esta centralidad de la copia puede también situarse en un enfoque sociológico más general sobre la reproducción cultural en sentido lato, tal como sugiere Bourdieu con su teoría del habitus ${ }^{3}$, en cuyo marco lo que se copia pueden ser desde gestos hasta fórmulas, pasando por modos de hacer artefactos. También durante el siglo XX, la memética y diversas variantes dentro de la socio-biología (entre las que se destacan Dawkins ${ }^{4}$ y Wilson ${ }^{5}$ ) han propuesto el modelo de copia como factor esencial a la hora de pensar la evolución cultural. Si seguimos este hilo argumentativo, parece haber cierto consenso interdisciplinar sobre la necesidad de incluir el concepto de copia o reproducción dentro de cualquier teoría satisfactoria tanto del cambio como de la estabilidad de nuestras prácticas culturales.

\footnotetext{
1 Como se aclarará en las siguientes secciones, el interés de este trabajo no es abordar a Benjamin de manera histórica, sino evaluar la fortaleza o adecuación de algunas de sus categorías en el contexto de la discusión contemporánea en filosofia de la técnica.

2 Leroi-Gourhan, A., El hombre y la materia. Evolución y técnica I, Madrid: Taurus, 1988.

3 Bourdieu menciona que la sociología se ha preocupado más por explicar los procesos de cambio que las modalidades que permiten la estabilidad cultural. Sobre estas últimas se monta su teoria del habitus. Sobre esta idea, cf. Bourdieu, P., Outline of a Theory of Practice, Cambridge: Cambridge University Press, 2013.

4 Dawkins, R., El gen egoísta. Las bases biológicas de nuestra conducta, Barcelona: Salvat, 1993. 5 Wilson, E.O., Sociobiology, Cambridge: Belknap Press, 1975.
} 
Ahora bien, en la medida en que nuestro interés reside en explorar la naturaleza de la copia en el ámbito técnico debemos ceñir nuestro análisis a casos de producción técnica paradigmática. Esta estrategia argumentativa no nos obliga a disponer de (o a postular implícitamente) una teoría general sobre la reproducción cultural. Si pensamos en un momento originario de la técnica, la replicación de una herramienta supone el reconocimiento de propiedades de materiales y formas, así como de su disposición, de lo cual emerge una función reconocible para los usuarios. Para dialogar con un caso particular, tomemos el caso de un hacha de piedra. La reproductibilidad de la herramienta "hacha de piedra" demandará: (1) un mango, probablemente de madera; (2) una cabeza con filo, probablemente de piedra; y (3) un modo de fijación, sea mediante incrustación en la madera o sujeción con una cuerda de fibras vegetales. La atribución de función y el reconocimiento de propiedades en los elementos disponibles en la naturaleza suponen una formalización muy elemental.

Respecto de este primer ejemplo primitivo de copia, la replicabilidad artesanal de herramientas en instancias posteriores supondrá un grado de formalización y relativa estabilidad de las formas y los materiales. Este proceso a su vez implica una normalización de los elementos, como sucede cuando aparecen las hachas de hoja metálica logradas mediante procedimientos de herrería. El molde del metal acotará la variación de la cabeza del hacha. Esto permite un mayor grado de previsión al mismo tiempo que supone una limitación de las variaciones en la serie. Cuando la normalización de los elementos se deriva de las necesidades técnicas del procedimiento de fabricación de los elementos, y no de las destrezas del artesano o los azares de lo que existe en la naturaleza, podemos hablar ya de una replicación estandarizada (y podríamos afirmar que es este tipo de replicación la que asegura la estabilidad y la fiabilidad que necesita una teoría de la reproducción cultural ya sea entendida en términos minimalistas o maximalistas).

Si seguimos a Stiegler ${ }^{6}$, para que algo sea considerado como propiamente técnico debe ser replicable más allá del descubrimiento personal o idiosincrático, como puede serlo el uso de ciertas herramientas por parte de animales no humanos. La replicación que respalda a todo fenómeno técnico genuino obedece, en verdad, a un proceso de abstracción y exteriorización que no resulta atribuible a comportamientos genéticos. En este marco, Stiegler propone una co-constitución de lo humano y la técnica mediante un proceso de exterio-

${ }^{6}$ Stiegler, B., La técnica y el tiempo I. El pecado de Epimeteo, Hondarribia: Editorial Hiru, 2002. 
rización que permite el desarrollo de la autoconciencia o producción de un interior. Sin la externalización de funciones y sentidos en inscripciones extracorporales (sean estas hachas de piedra, pinturas en las paredes o palabras), resulta imposible pensar una interioridad. Y tal externalización permite tomar conciencia del tiempo y registrarlo. Esta operación de co-constitución gradual en un proceso evolutivo que se extiende por siglos permite ubicar a la copia en tres instancias diferentes: la genética, la epigenética y la epifilogenética. La primera instancia corresponde a toda replicación no aprendida por imitación o abstracción; la segunda a aquellas que se desarrollan a partir del aprendizaje en el transcurso vital del individuo ${ }^{7}$; la tercera, aquella que permite la continuación de la especie por otros medios que su propio cuerpo. Si aceptamos la propuesta stigleriana, esta tercera instancia constituye lo propiamente técnico de lo que se deriva la centralidad de la reproducción artefactual. El nivel epifilogenético supone el reconocimiento de las funciones de la herramienta más allá del cuerpo (y presencia) de su creador funcionando como memoria exteriorizada, cuya función puede ser reconocida, y por ello, replicable. En esta tercera instancia, la técnica se compone como lenguaje, pero también "utillaje", una gramática de las acciones inscritas en los usos reconocibles de la herramienta: se trata de prestar atención a la originalidad del proceso epigenético que se pone en marcha desde el momento en que aparece el utillaje, en tanto que se conserva en su forma más allá de los individuos que lo producen o lo utilizan. (La aparición de este utillaje, verdadera memoria no viva y sin embargo vital, materia inorgánica aunque organizada, indispensable para la definición del organismo humano, supone, en tanto que vector y acumulador de las epigénesis pasadas, una singular plasticidad epigenética de la estructura cerebral). En la vida no artificial, no técnica, no articulada por la diferencia, cualquier orden de acontecimientos epigenéticos está perdido para la memoria específica con la pérdida del individuo que ha sido su soporte. En el caso que nos ocupa, la vida conserva y acumula esos acontecimientos.

\footnotetext{
7 En estas instancias podríamos ubicar las discusiones en torno a la "técnica" de los animales no humanos. Para una discusión sobre esta última categoría, $c f$. Crelier y Parente, "La tecnicidad humana y animal en un marco naturalista. Problemas y perspectivas en el debate contemporáneo", en: Filosofía UIS, v. XIII, 2 (2014), pp. 17-36; y Cuevas, A., "Artefactualidad animal", en: Ludus Vitalis, v. XXIV, 45 (2016), pp. 155-174.

8 Cf. Stiegler, B., La técnica y el tiempo I. El pecado de Epimeteo, p. 262. Esta cita de Stiegler nos interesa porque aborda el problema de la producción de objetos como un fenómeno que co-constituye lo humano y la técnica, en particular por la persistencia de objetos más allá de la vida del sujeto. Si bien esta lectura excede la tesis de la reproductibilidad benjamineana permite contextualizar en un marco filosófico de mayor alcance el problema de la copia.
} 
La capacidad de replicación de entidades "inorgánicas organizadas" (sean estas palabras o herramientas) cuya comunicabilidad sobreviva al creador es la base de una teoría de la técnica. Y de acuerdo con Stiegler ${ }^{9}$, tal estandarización es el vector para los procesos de industrialización.

El proceso de estandarización de la producción marca la emergencia de un nuevo tipo de objeto en el siglo XIX: "aquel que es como es porque las máquinas que lo producen son como son. El rumbo de la forma del objeto industrial sigue a la del sistema técnico de producción en mayor medida que a la tradición artesanal" ${ }^{10}$. Con todo, el problema de la entidad de lo seriado en sus distintas etapas (tipo primitivo, estereotipo artesanal, objeto estandarizado industrial) constituye un objeto de indagación más bien marginal dentro de la filosofia de la técnica, y es esta condición la que motiva en parte la exploración realizada en este artículo.

Al contrario de lo que sucede en filosofia de la técnica, el problema de la copia sí ha recibido mucha atención en la teoría del arte y en la estética contemporáneas, en especial para pensar la distinción entre obra de arte y artefacto, para discutir la relevancia de la originalidad para la valoración de la autoría, o bien para determinar la adecuación de una obra particular a un género dado. Sin embargo, acaso el abordaje más fértil que se pregunta por la ontología de la copia sea el que propuso el filósofo alemán Walter Benjamin en su célebre ensayo sobre la obra de arte. En este trabajo nos interesa abordar, a partir del hilo conductor de dicho ensayo, una serie de aporías ontológicas y políticas que giran alrededor de la naturaleza de la copia. Como se verá más adelante, nuestro objetivo no consiste en dar cuenta de un aspecto específico interno de la teoría benjaminiana, sino más bien en leer a Benjamin qua filósofo de la técnica, es decir, evaluar si algunas de sus intuiciones generadas al calor de la cultura de masas de siglo XX pueden hoy en día ser filosóficamente valiosas una vez recontextualizadas en el debate contemporáneo de filosofia de la técnica.

\section{Walter Benjamin como filósofo de la técnica}

Hay dos problemas que nos permiten encuadrar grosso modo a Benjamin como "filósofo de la técnica". Se trata, en verdad, de dos problemas entrela-

\footnotetext{
9 Ibid., p. 110.

10 Sandrone, D., "La especificidad del objeto industrial y la ontología de los objetos técnicos: acerca de los enfoques semánticos y sintácticos de la tecnologia”, en: Quadranti. Rivista internazionale di filosofia contemporánea, v. IV, 1-2 (2016), p. 220.
} 
zados. El primero de ellos es taxonómico, pero -en rigor- no solo taxonómico: ¿constituye el ensayo sobre la obra de arte un enfoque sustantivista (siguiendo la terminología de Feenberg $\left.{ }^{11}\right)$ ? ¿En qué categoría de tipo axiológico deberíamos situar a Benjamin? El segundo problema tiene que ver con una de las críticas que le hacen Hennion y Latour en un artículo de intención polémica ${ }^{12}$ : ¿es Benjamin un idealista disfrazado de materialista a la hora de analizar las obras y los medios técnicos? ¿O bien se trata de un materialismo de signo extraño y singular? Esta sección intenta responder a la primera pregunta explorando algunos de sus solapamientos e imbricaciones con la segunda cuestión a partir del análisis del estatuto de la copia reproductible y de las implicaciones ontológicas y políticas del fenómeno mismo de reproducción técnica.

2.1. La posición de Benjamin en relación con las líneas contemporáneas de filosofia de la técnica en su dimensión axiológica

A fin de pensar cómo ubicar el ensayo de Benjamin dentro del territorio de indagación contemporáneo tomaremos en principio la taxonomía propuesta por Feenberg en Questioning Technology. Esta estrategia nos permitirá iluminar algunas ambigüedades relevantes de la posición benjaminiana.

En breves términos, Feenberg entiende que las variables de neutralidad y carga de valores asignadas por cada autor a la tecnología pueden ser combinadas con la atribución de autonomía o controlabilidad. En este sentido surgen cuatro alternativas conceptuales: el sustantivismo (que sostiene que las tecnologias son autónomas y se hallan cargadas de valores), el instrumentalismo (que defiende la neutralidad de la tecnología y la capacidad de control humana), el determinismo (que enfatiza el carácter autónomo de la técnica al tiempo que afirma su neutralidad) y, finalmente, la teoría crítica (que admite que la tecnología puede ser controlable pero está cargada de valores). Si bien tiene algunas debilidades -que serán señaladas en el argumento de este mismo artículo-, el mapa de alternativas sugerido por Feenberg permite encuadrar de mejor manera los interrogantes anteriormente planteados. 


\begin{tabular}{|l|l|l|}
\hline Tecnología es & AUTÓNOMA & CONTROLADA POR HUMANOS \\
\hline $\begin{array}{l}\text { Neutral } \\
\text { (completa separación de } \\
\text { medios y fines) }\end{array}$ & $\begin{array}{l}\text { DETERMINISMO } \\
\text { (marxismo tradicional) } \\
\text { Marx } \\
\text { Lynn White }\end{array}$ & $\begin{array}{l}\text { INSTRUMENTALISMO } \\
\text { (fe liberal en el progreso) } \\
\text { Tecnólogos y científicos } \\
\text { Sentido común }\end{array}$ \\
\hline $\begin{array}{l}\text { CARGADA DE VALORES } \\
\text { (los medios conforman un } \\
\text { modo de vida que incluye } \\
\text { a fines) }\end{array}$ & $\begin{array}{l}\text { SUSTANTIVISMO } \\
\text { (medios y fines conectados } \\
\text { en sistemas) }\end{array}$ & $\begin{array}{l}\text { TEORÍA CRÍTICA } \\
\text { (es posible elegir sistemas } \\
\text { medios/fines alternativos) }\end{array}$ \\
& $\begin{array}{l}\text { Jacques Ellul } \\
\text { Heidegger } \\
\text { Weber } \\
\text { Mc Luhan }\end{array}$ & $\begin{array}{l}\text { Marcuse } \\
\text { Foucault }\end{array}$ \\
\hline
\end{tabular}

Figura 1. Enfoques axiológicos sobre la tecnología según Feenberg

Una vez presentado este marco hermenéutico, ¿qué posibilidades de interpretación ofrece el célebre ensayo de Benjamin ${ }^{13}$ ? Si tomamos el aspecto político del ensayo en sus cuatro versiones, específicamente el valor de emancipación que Benjamin atribuye a algunas nuevas técnicas como el cine, entonces la posibilidad de control sobre la técnica parecería estar asegurada, lo que permitiría incluir al autor dentro de la "teoría crítica" (que Feenberg asocia principalmente con Marcuse y Foucault). Sin embargo, el ensayo sugiere una cierta inmanencia del medio técnico, enfatizada en las lecturas más difundidas sobre la "pérdida del aura", que lo emparentarian al sustantivismo. La idea de que los medios de reproducción técnica mantienen una suerte de ambigüedad valorativa, por otra parte, podría aproximarlo a cierta forma de instrumentalismo. Como señala en el Epílogo de su ensayo, en manos fascistas dichos medios resultan una amenaza, mientras que bajo el mandato de una "politización del arte" ${ }^{14}$ serían progresivos y emancipatorios en la medida en que favorecerían la destrucción de la codificación burguesa de la cultura. Sin embargo, en la medida en que las técnicas están cargadas de valores para Benjamin, no es apropiado clasificarlo dentro del instrumentalismo. Consideramos entonces que para situar a Benjamin en relación con la filosofia de la técnica es necesario conceptualizar su abordaje y el modo en que incorpora el carácter polivalente de lo artificial.

En este punto es necesario ofrecer una definición provisoria de polivalencia. Para Benjamin la técnica no es neutral en tanto modifica el orden de lo existente a través de la creación de un conjunto de operaciones y posibilidades que alteran el universo mismo de los fines. Efectivamente los artefactos 
y sistemas técnicos están cargados de valores e integrados a sistemas mayores con fines que les son propios. Pero a diferencia de las posiciones sustantivistas, no hay en la propuesta benjaminiana una teleología inherente, no hay una autonomía completa del objeto técnico que impida cierta modalidad de control humano. Y, a diferencia de las posiciones de la teoría crítica, las posibilidades de elección no se dan entre medios o tecnologías alternativos; más bien, se trata de elecciones inherentes al nuevo orden de posibles que los fenómenos técnicos instauran. No se trata de elegir otras tecnologias sino de disputar políticamente el orden de posibles dentro de las mismas nuevas tecnologías, en el marco acotado de posibilidades que estas instauran. ¿Qué significa disputar dentro de las mismas tecnologias? Las opciones se refieren a tres aspectos de la tecnología reproductiva: a) a los artefactos, b) a los usos de los mismos, o c) a los efectos o consecuencias sociales. Cada uno tiene matices que impide una unificación completa. La posibilidad de opción sobre el primer aspecto no aparece siquiera considerada en el ensayo ya que la irrupción de la reproductibilidad técnica es un hecho innegable del mundo contemporáneo al ensayo. Una elección sobre el segundo aspecto parece más afin a las instancias de discusión y clausura sociotécnica tal como la conciben Pinch y Bijker ${ }^{15}$ y encaja coherentemente, además, con la oscilación que marca Benjamin entre usos emancipatorios y usos totalitarios. La tercera alternativa, centrada en los efectos, parece estar ya descartada en una lectura inmanentista ya que no serian controlables. La atribución de la idea de polivalencia técnica a Benjamin permite, de este modo, asumir un margen de elección acotado, en tanto la irrupción de la nueva tecnología modifica también el modo de existencia preexistente, tanto de lo artístico como de lo social. En términos de Benjamin, las tecnologías reproductivas hacen posible la cultura de masas, sin que esto signifique que dichas tecnologias determinen necesariamente una cierta forma de vida social (lo cual nos conduciría, como veremos más adelante, a un argumento determinista).

Veamos ahora con mayor detenimiento las posibles relaciones del ensayo de Benjamin con las cuatro categorías propuestas por Feenberg. La idea de "destrucción" o "decadencia" del aura podría ser leída como un énfasis en la inmanencia del medio técnico y en el modo en que este establece un conjunto de "decisiones" técnicas que no parecieran estar relacionadas con los contenidos o usos ocasionales que se hagan de él. Buena parte de esta lectura se

\footnotetext{
15 Pinch, T. y W. Bijker, "The Social Construction of Facts and Artefacts: Or How the Sociology of Science and the Sociology of Technology Might Benefit Each Other”, en: Social Studies of Science, v. XIV, 3 (1984), pp. 399-441.
} 
explicita en el modo en que Benjamin piensa al cine y su nuevo orden técnico de reproductibilidad. Cabe recordar que el fenómeno de la "pérdida" o "decadencia" del aura (a la par de la pérdida en la capacidad de hacer o transmitir "experiencia" presentada en el ensayo sobre el impacto de la tecnología reproductiva de la imprenta en "El narrador") son argumentos recurrentes para leer a Benjamin como sustantivista, a partir de una pérdida de valores derivados de la inadecuación de los nuevos modos industriales de producción con respecto a las capacidades motrices y perceptivas del cuerpo humano. Esta vía permite a Löwy rotular a Benjamin como un marxista antiprogresista ${ }^{16}$ y "romántico"17. O extremar la relación entre técnica moderna y pérdida como hace Agamben ${ }^{18}$ al postular directamente la "muerte de la experiencia" y así intentar conciliar a Benjamin con el Heidegger de Gelassenheit.

Si seguimos esta línea interpretativa, el argumento de Benjamin podría encajar dentro del enfoque sustantivista. Pero el principal obstáculo para tal interpretación es que el filósofo alemán no considera a la tecnología como una suerte de entidad autónoma. Además hay aquí dos omisiones que habilitan la lectura sustantivista. La primera es que se olvida frecuentemente que en el ensayo de la obra de arte se habla de una "oscilación" que introduce la reproductibilidad técnica: del polo cultual al polo exhibitivo. Y en esta clave no sustantivista debería leerse el epígrafe de Valery que abre la tercera versión del ensayo: “...Pero el acrecentamiento sorprendente de nuestros medios, la flexibilidad y la precisión que estos alcanzan, las ideas y costumbres que introducen, nos aseguran respecto de cambios próximos y profundos en la antigua industria de lo Bello. En todas las artes hay una parte física que no puede ser tratada como antaño, que no puede sustraerse a la acometividad del conocimiento y la fuerza modernos. Ni la materia, ni el espacio, ni el tiempo son, desde hace veinte años, lo que han venido siendo desde siempre"19.

Además, la lectura sustantivista esencializa el concepto de "aura" a partir de lo presentado en el ensayo de la obra de arte y desconoce la génesis eminentemente técnica del concepto original de "aura" y sus diversas formulaciones previas y posteriores en el pensamiento benjamineano. Retomando una

${ }^{16}$ Cf. Löwy, M., Walter Benjamin: aviso de incendio: Una lectura de las tesis "Sobre el concepto de historia", Buenos Aires: FCE, 2002, p. 23.

17 Ibid., p. 31.

18 Agamben, G., Infancia e historia: Destrucción de la experiencia y origen de la historia, Buenos Aires: Adriana Hidalgo, 2007, pp. 7-10.

19 Benjamin, W., "La obra de arte en la época de su reproductibilidad técnica", p. 25, Nota 2. 
sistematización previa ${ }^{20}$, se pueden señalar valencias del "aura". Una valencia técnica de la "Pequeña Historia..." que pone en relieve el estadio artesanal de la técnica fotográfica como un momento de quiebre: "Había un aura alrededor de ellas, un medium que da a su mirada, en cuanto esta lo atraviesa, plenitud y seguridad. Y una vez más el equivalente técnico de esto resulta evidente; consiste en el continuo más absoluto de la más clara luz a la más oscura sombra" ${ }^{21}$.

Y poco más adelante señala que el aura de los incunables de la fotografia no era, "de hecho, el mero producto de una cámara primitiva. En esas épocas el objeto y la técnica se corresponden tan nítidamente como se desligarán en el periodo de decadencia que le siguió" 22 . Esta primera definición de "aura" de 1931 laiciza y desromantiza otras dimensiones presentes en "La obra de arte..." al postularla como un efecto físico propio de un procedimiento específico ${ }^{23}$. Esa valencia técnica se complementa con otra de orden perceptivo, asociada a los aspectos temporal y espacial, en la conocida formulación del aura como la manifestación irrepetible de una lejanía por más cerca que se pueda estar, presente tanto en "Pequeña historia..." como en "La obra de arte...". Tal sentido de "aura" sienta las bases para la distinción entre lo aurático y lo serial a partir del valor cultual, primero sagrado, y luego secular, específica de "La obra de arte..." (con la demanda de originalidad del arte propia del romanticismo y de unicidad asociado a un objeto "original", es decir, al que se le puede atribuir autoría a partir de rasgos materiales autográficos como la firma del pintor ${ }^{24}$.

\footnotetext{
${ }^{20}$ Berti, A., “Aura y técnica”, en: Vera, T. (ed.), Walter Benjamin. Estética de la imagen, Buenos Aires: La Marca, 2015, pp. 205-217.

${ }^{21}$ Benjamin, W., "Breve historia de la fotografia", en: Estética de la imagen, Buenos Aires: La Marca, 2015, p. 95. Todas las cursivas en esta y en las citas subsiguientes son de los textos originales.

22 Ibid., p. 97.

23 Ibid., pp. 91-97.

24 Asimismo, cabe señalar que hay también una formulación subjetivista del "aura", asociada a la "memoria involuntaria" y opuesta a la "dureé", que actualiza un campo emocional (a la vez perceptivo y racional) en el que su decadencia se vive como una pérdida, presente en el ensayo sobre Baudelaire. Este énfasis en la pérdida, presente en versiones del ensayo de la obra de arte y presente en este último ensayo, es el que permitiria pensar la mirada de Benjamin sobre la técnica como sustantivista. Hay un cambio en los valores que la tecnología introduce y que supone una pérdida. En esta versión, el "aura" cobra otra dimensión y se relaciona con la "memoria involuntaria", y con la oposición que desarrolla entre mera "vivencia" frente a "experiencia" auténtica, y entre el "spleen" frente al "aura": "La 'dureé' en la que se ha saldado la muerte, tiene la mala infinitud de un ornamento. Excluye que se le aporte toda tradición. Es la vivencia por antonomasia que se pavonea en el traje prestado de la experiencia. El spleen, por el contrario, expone la vivencia en su desnudez. El melancólico ve con terror que la tierra recae en un estado meramente natural. No exhala ningún hálito de prehistoria. Ningún aura" ( $C f$. Benjamin, W., "Sobre algunos temas en Baudelaire", en: Iluminaciones II. Poesía y capitalismo, Madrid: Taurus, 1998, p. 160).
} 
De la crítica a los efectos de la modernización burguesa no se desprende necesariamente un argumento sustantivista, sino que se señala una descontextualización respecto de la tradición operada por la mercantilización que destruye lo aurático para luego simularlo (bajo la figura del ornamento). Lo que en una técnica artesanal dada se derivaba por necesidad del procedimiento, en la otra industrial es un adorno innecesario. Así, el efecto de lo reproductivo en estos ensayos no es en modo alguno neutral sino que va adquiriendo diversas valencias a la vez inmanentes y trascendentes, sin ser tampoco determinista, como discutiremos en el próximo apartado.

\section{Los aspectos inmanentes del medio técnico}

La sección anterior ha ofrecido una lectura que no identifica estrictamente a Benjamin con ninguna de las cuatro categorias axiológicas propuestas por Feenberg. Como veremos, la noción de inmanencia puede ayudarnos a salir del embrollo conceptual atado a las categorias de sustantivismo y determinismo, pues no equivale a autonomía (es decir, no permite montar un argumento determinista o sustantivista puro), pero al mismo tiempo reconoce aspectos intrínsecos de los medios técnicos que se sustraen a la elección de los usuarios y a su horizonte de deliberación. De hecho, tal como ahondaremos en la penúltima sección, buena parte de las tensiones internas del argumento de Benjamin surge por la admisión de cierto enfoque inmanentista sobre las mediaciones técnicas.

Retornemos ahora al ejemplo del cine, un arte paradigmático para lo que Benjamin comprende como "época de la reproductibilidad" ${ }^{25}$. Para el filósofo alemán, lo relevante no es cómo se usa el cine, con qué contenidos políticoideológicos lo completamos (lo cual implicaría su aspecto "trascendente"), sino más bien qué nuevas modalidades de consumo genera, qué transformaciones profundas conlleva en la trama misma de la relación obra/espectador, cómo reformula el concepto mismo de "obra", etcétera. En otras palabras, a Benjamin le interesa estudiar las novedades del potencial técnico del cine en cuanto medio material. Y estos aspectos son conceptualmente independientes de los usos que se haga del cine. Más bien, son aspectos inmanentes al medio técnico en cuestión. Es importante, entonces, aproximarnos a una caracterización del enfoque

\footnotetext{
${ }^{25}$ La fonografia no recibe la misma atención, aunque el proceso de producción de los discos "de estudio" podría ser objeto de un análisis similar al de las secciones IX a XVIII del ensayo que se ocupan del cine. Esta ausencia acaso se deba a la masividad relativamente acotada de la industria del disco en comparación con el cine en ese periodo.
} 
inmanentista que subyace en Benjamin a fin de alcanzar una diferenciación suficientemente clara con respecto a las categorias de sustantivismo y determinismo. A fin de lograr este cometido, exploraremos tres rasgos básicos del inmanentismo.

Una lectura que admite que hay rasgos inmanentes en los medios técnicos subraya, en primer lugar, el hecho de que los nuevos medios disponen de una arquitectura que implica en sí misma una transformación cognitivo-agencial de los agentes atados a su entorno. Por supuesto, el objetivo o finalidad de estos nuevos medios no es en sí mismo la transformación de dichas capacidades, pero la inserción de dichos medios en el contexto cultural genera ese efecto independientemente de las intenciones de sus diseñadores. Tomando el caso analizado por Benjamin, el cine no nace con la función de adoctrinar a las masas, o la de diluir la concepción burguesa de la cultura, pero hay algo en el dispositivo material del cinematógrafo que -independientemente de las intenciones que podrian llegar a guiar los usos- debilita y/o cuestiona el espacio de representación del teatro, modifica la relación auditorio-obra, etcétera. En otras palabras, el medio técnico selecciona un conjunto de acciones óptimas estables a lo largo del tiempo, mientras que inhibe otro conjunto. De tal modo, un primer rasgo de la inmanencia del medio técnico es este tipo de independencia respecto a las intenciones y objetivos humanos.

Un segundo aspecto a señalar nos remite a la esfera de aplicación del enfoque inmanentista. Este último se mueve en un terreno en el que importa la materialidad del medio en sí mismo, sus correlaciones internas y sus vínculos con otros objetos técnicos. En esta aproximación, las medidas antropocéntricas habituales (la "utilidad" de un artefacto, su "función", su "poder simbólico", su "eficacia", entre otras) tienden a quedar fuera de foco. De alguna manera esta estrategia inmanentista estaría en consonancia con el denominado "giro ontológico" en filosofía y ciencias humanas ${ }^{26}$. En este aspecto se explicita la diferencia con el determinismo, que tiene su punto de partida en la pregunta más genérica por la relación entre tecnología y sociedad, puntualmente orientada a dar cuenta de cómo una determina a la otra, bajo qué modalidades se presenta dicha determinación, etcétera ${ }^{27}$-es decir, un tipo de interpreta-

\footnotetext{
${ }^{26}$ Holbraad, M. y M. Pedersen, The Ontological Turn. An Anthropological Exposition, Londres: Cambridge University Press, 2017; Harman, G., Hacia el realismo especulativo, Buenos Aires: Caja Negra, 2015.

${ }^{27}$ Bimber, B., “Tres caras del determinismo tecnológico", en: Smith, M. y L. Marx (eds.), Historia y determinismo tecnológico, Madrid: Alianza Editorial, pp. 95-116; Parente, D., "Algunas precisiones sobre el determinismo tecnológico y la tecnología autónoma. Una lectura sobre la filosofia de Langdon Winner", en: Redes, v. XII, 23 (2006), pp. 79-102.
} 
ción "humanista" en la cual la división entre personas y cosas, humanos y no-humanos, permanece asegurada-. Las oposiciones teatro/cine, o pintura/ fotografia, abordadas insistentemente en el ensayo de Benjamin se juegan, en cambio, en un micro-territorio que se sustrae a la formulación en términos deterministas. Aquello que está en juego no son las categorías "tecnologia" y "sociedad" sino, más bien, las micro-tensiones dialécticas que hacen que la preeminencia de un medio material se haga al costo del debilitamiento de otro medio material. En resumen, si bien Benjamin adjudica un peso importante a la inmanencia del medio técnico, este rasgo no lo convierte en determinista.

Un tercer aspecto de los enfoques inmanentistas es que nos llevan a pensar en la dinámica intrínseca atada a ciertas innovaciones técnicas, concretamente en cómo ciertos nuevos entrelazamientos entre agentes, objetos y procesos técnicos implican tal densidad que, una vez inmersos en una determinada trayectoria, ya resulta difícil desde el punto de vista económico y pragmático realizar un retroceso a fin de alcanzar el estadio técnico anterior. Lo interesante de este enfoque es que explora cómo una cierta transformación en el ámbito de producción técnica no solo trae modificaciones y realineamientos en el orden social y cognitivo (es decir, en el orden de los usuarios humanos que fue analizado en el primer rasgo), sino también en el orden de los no-humanos ${ }^{28}$. Una modificación técnica importante puede generar un nuevo entrelazamiento entre cosas y cosas; puede fortalecer y estabilizar nuevos ensambles entre entidades no humanas ${ }^{29}$.

Un ejemplo interesante para analizar este fenómeno es el caso de la máquina de vapor, patentada por James Watt en 1784. Un correlato inherente

\footnotetext{
${ }^{28}$ Latour, B., Reensamblar lo social. Una introducción a la teoría del actor-red, Buenos Aires: Manantial, 2005.

${ }^{29}$ Si bien no nos detendremos en ello, uno de los efectos colaterales de la interpretación aquí propuesta es que la taxonomía de Feenberg es insuficiente para captar apropiadamente las posiciones de autores como Benjamin. Todo el conjunto de dependencias y codependencias entre entidades humanas y no humanas articuladas en una cultura material alteran la misma idea de lo que significa tener un "control total" sobre la técnica, así también como nuestra imagen de una dependencia completa respecto de ella. En rigor, varios marcos teóricos más complejos, como el co-evolutivo ( $c f$. Boivin, N., Material Cultures, Material Minds. The Impact of Things on Human Thought, Society and Evolution, Nueva York: Cambridge University Press, 2008), la idea de entanglement (cf. Hodder, I., Entangled. An Archaeology of the Relationships between Humans and Things, Londres: Wiley-Blackwell, 2012) o la de co-constitución de humanidad y técnica (cf. Stiegler, B., La técnica y el tiempo I. El pecado de Epimeteo, Hondarribia: Editorial Hiru, 2002), permiten una mejor comprensión de la dinámica de estos conjuntos biotécnicos. Con todo, discutir la taxonomía de Feenberg nos permite echar luz sobre las zonas grises del pensamiento sobre la técnica (y el problema de la copia en particular) en la obra de Benjamin, así como luego lo haremos con la crítica que proponen Latour y Hennion en el próximo apartado.
} 
a la introducción de la máquina de vapor en el sistema productivo es que la producción se independiza respecto a las anteriores fuentes de energía utilizadas (hidráulica o animal). Como consecuencia de este rasgo intrínseco, la industria comienza a abstraerse geográficamente de sus anteriores restricciones de funcionamiento. Como se habrá notado, ninguna de estas transformaciones históricas en el ámbito de la cultura material está relacionada con los usos o significados del nuevo sistema técnico. Se trata, por el contrario, de condiciones intrinsecas de optimidad que se desatan una vez que el nuevo sistema se pone en marcha. Dicho aspecto inmanente de la técnica fue estudiado por Karl Marx en el primer volumen de El capital, donde analiza precisamente el reformateo de habilidades y de escenarios productivos atados al poder del vapor. Pero, en términos generales, también tiene otros representantes relevantes en Jacques Lafitte, Gilbert Simondon ${ }^{30}$ y Marshall McLuhan. El caso de McLuhan es particularmente relevante como punto de comparación con Benjamin debido a la serie de tópicos que comparten en su investigación. La orientación inmanentista del canadiense es asimismo explícita en su conocido eslogan "el medio es el mensaje". Las consecuencias individuales y sociales de cualquier medio "resultan de la nueva escala que introduce en nuestros asuntos cualquier extensión o tecnología nueva" ${ }^{\text {" }}$. Para el autor, los medios técnicos disponen de cuatro leyes inmanentes (aumento, obsolescencia, inversión, recuperación) que no están relacionadas con sus heterogéneos usos en este u otro lugar del planeta. Lo que importa a la hora de conceptualizar a los medios técnicos no es su contenido o su utilización contingente sino los nuevos sentidos y destrezas que despierta, las capacidades que debilita, las nuevas relaciones que genera entre humanos y cosas, así también como entre cosas y $\operatorname{cosas}^{32}$. El contenido o mensaje de un medio particular tiene tanta importancia como el texto impreso en el casco de una bomba: ninguna ${ }^{33}$. En este contexto la diferencia invocada es entre contenidoy forma, con la preeminencia de esta última sobre la primera. Un

\footnotetext{
${ }^{30}$ Para un estudio de las relaciones entre las propuestas de Lafitte, Simondon y Marx, véase Sandrone, D., Aportes para una nueva concepción del diseño tecnológico: Un estudio filosófico de su naturaleza y su rol en el cambio tecnológico, Tesis (Fil.), Córdoba: Universidad Nacional de Córdoba, 2016.

${ }^{31}$ McLuhan, M., Comprender los medios de comunicación. Las extensiones del ser humano, Barcelona: Paidós, 2009, p. 31.

${ }^{32}$ Como bien indica Harman, la idea mcluhaniana de que los medios técnicos tienen a la inversión como una ley favorece que haya tantas puertas de salida, tantos bucles en el despliegue de cada medio, que hace imposible una lectura de McLuhan como determinista tecnológico (cf. Harman, G., Hacia el realismo especulativo, Buenos Aires: Caja Negra, 2015, pp. 247-249).

${ }^{33}$ McLuhan, M. y E. McLuhan, Leyes de los medios. La nueva ciencia, México: Alianza, 1990.
} 
caso de análisis que presenta McLuhan es el alfabeto: no constituye solo una nueva forma de registro de información, sino una transformación cualitativa del valor del espacio acústico y del modo de relacionarnos con él. A través del alfabeto, el espacio acústico (inherentemente discontinuo) se transforma en un espacio visual continuo que da primacía a la visión y a la linealidad, entre otros rasgos. A su vez, como bien ha investigado Walter Ong, independientemente de sus usos fácticos heterogéneos, la escritura potencia una serie de habilidades que no estaban previamente configuradas en el marco de las culturas orales ${ }^{34}$.

En resumen, los tres rasgos de un enfoque inmanentista anteriormente reconstruidos permiten, por una parte, asociar a Benjamin con tal posición $\mathrm{y}$, por otra, distinguirlo de las versiones hegemónicas de sustantivismo y determinismo tecnológico.

\section{La copia benjaminiana}

Uno de los problemas para insertar a Benjamin qua filósofo de la técnica en la taxonomía propuesta por Feenberg es la acumulación de lecturas contrapuestas sobre aspectos que rodean al concepto de "aura", cuando lo más relevante para pensar la técnica en Benjamin es su concepto de "copia". A propósito de esto, Schwarzbock señala que son precisamente las obras seriadas las que hacen a las obras previas portadoras "retroactivas" de aura: "El aura como concepto estético no existiría sin la fotografia y el cine. Las artes que no tienen aura crean el aura" ${ }^{35}$.

Como ya señalamos anteriormente, hay un momento aurático de la fotografia que es un momento técnicamente producido, pero en una instancia pre-industrial. Se trata de un aspecto no muy considerado pero particularmente relevante ya que articula la figura del artesano de "El narrador" con la figura de los pioneros de la fotografia. Esa relación se establece en torno a las primeras fotografias, retratos mecánicamente producidos por técnicos especializados: "estas primeras personas reproducidas entraban al espacio visual de la fotografia sin tacha, o, mejor dicho, sin aclaración escrita. Los periódicos eran todavía

\footnotetext{
${ }^{34}$ Ong, W., Oralidad y escritura: Tecnologías de la palabra, Ciudad de México: FCE, 1987. En rigor, no sería erróneo remontar este argumento inmanentista al Fedro de Platón, donde denuncia el efecto debilitante que tendrá la escritura sobre la memoria: "Porque es olvido lo que [las letras] producirán en las almas de quienes las aprendan, al descuidar la memoria, ya que, fiándose de lo escrito, llegarán al recuerdo desde afuera, a través de caracteres ajenos, no desde dentro, desde ellos mismos y por sí mismos" (c $f$. Fedro 275a-275b)

35 Schwarzböck, S., Los monstruos más fríos: Estética después del cine, Buenos Aires: Mardulce, 2017, p. 29.
} 
objetos de lujo que rara vez se compraban y que más bien se les echaba una mirada en el café; el procedimiento fotográfico todavía no se había convertido en herramienta... En resumen: todas las posibilidades de este arte del retrato se basaban en que aún no había tenido lugar el contacto entre actualidad y la foto"36.

En el diagnóstico benjaminiano sobre el mundo previo a la reproductibilidad técnica, el retrato devuelve la mirada del ser querido, así como las últimas palabras del moribundo transmiten experiencia a aquellos en torno a su lecho. Rostros y narraciones cobran sentido en relación con tradiciones que aún dominan y a la comprensión de sus procesos productivos. Esta lectura no es nostálgica, solo descriptiva. El cambio de fondo se da con la aparición de la fotografia instantánea, desprovista de aura, y de la información pura de las noticias de los periódicos, descontextualizada respecto de la narración oral, dos fenómenos que caracterizan la etapa de la industrialización de la percepción. La aceleración de la percepción descontextualiza los estímulos de la tradición que les daba sentido, y los torna inasimilables. La carga valorativa asociada a estos fenómenos puede inducir a pensar su posición como afin al sustantivismo de Heidegger en la oposición entre "técnica" y "técnica moderna", por ejemplo. Para Benjamin, sin embargo, el problema es uno de contenido pero también de forma (y en esto se diferencia de McLuhan): "estetizar" es hacer como si la técnica fuera solo un medio, como se deriva de la crítica a la falsificación del aura en la etapa industrial mediante el uso de goma bicromatada para simular el aura que antes era resultado del proceso técnico artesanal ${ }^{37}$. El problema no está en que con la instantánea se "pierda" el aura de la fotografia; el problema está en la reinserción artificial del efecto para preservar el fetiche de la imagen aurática.

Benjamin discute con las teorias e historias del arte (liberales y fascistas) a partir de establecer relaciones entre "aura" y "experiencia" desde una perspectiva materialista. Esta operación incorpora la (posible) politización que el nuevo medio habilita. Si consideramos a Benjamin como un filósofo de la técnica, no se trata de una pérdida de esencias que comporten una deshumanización, sino de fenómenos históricos de orden técnico que inauguran nuevas posibilidades en el orden de lo político. Un ejemplo de esta posición son las posibilidades de autoconocimiento que ve en el cine ruso posterior a la revolución. En una defensa de Acorazado Potemkin, señala: "Las revoluciones técnicas: esos son

36 Benjamin, W., "Breve historia de la fotografia", p. 91.

37 Ibid., p. 97. 
los puntos de fractura del desarrollo del arte en que... las tendencias se hacen visibles, quedan expuestas, por así decir. En cada nueva revolución técnica, la tendencia se convierte, como por sí misma, a partir de un muy oculto elemento del arte en uno manifiesto. Y con eso llegariamos por fin al cine. Entre los puntos de fractura de las formaciones artísticas el cine es uno de los más potentes. Realmente, con él surge una nueva región de la conciencia"38.

La posibilidad de las masas de verse a sí mismas como masas en la pantalla en el ámbito colectivo de la proyección es lo que hace visible esa nueva región. La cita es indicativa de la indisociabilidad que, en ciertas obras, hay entre forma y contenido, que a la vez ponen en relación sus aspectos inmanentes (de orden técnico) con los políticos (la "tendencia"). Las distintas formas de reproductibilidad técnica suponen una apertura de posibilidades ${ }^{39}$. Desde este marco, la reproductibilidad inaugura una ruptura del orden conservador de la tradición (y de las tecnologías previas en la que se sustenta) posibilitada por la técnica reproductiva. Pero cabe señalar que, en tanto no es una posición determinista, puede ser apropiado por el fascismo, que propicia una falsa neutralidad de la técnica en la continuación del orden cultural previo mediante la utilización de las tecnologias industriales. Al hacer como si nada cambiara y el medio fuera transparente, sosteniendo la ilusión de la separación de forma contingente y contenido esencial, la reproductibilidad admite otros usos. Sin embargo, tales usos comportan otros valores: en el caso del fascismo, la supuesta transparencia de la técnica por la cual la relación entre forma y contenido no se vería afectada.

Las figuras difusas del politécnico, del cineasta ruso y del autor como productor que presenta en distintos ensayos ofrecen una clave para conducir este nuevo orden perceptual en una dirección política antes que en una estetizante o nostálgica. Tal lectura permitiría enmarcar de manera apresurada a Benjamin en lo que Feenberg (que casi no lo nombra en Questioning Technology) sistematiza como la perspectiva de la "teoría crítica" ya que postularian la posibilidad de elección de medios o fines alternativos. Solo que esta categoría,

${ }^{38}$ Benjamin, W., "Réplica a Oscar A. H. Schimtz", en: Estética de la imagen, Buenos Aires: La Marca, 2015, p. 148.

39 Por caso, la nueva función del escritor en el contexto de la industria cultural del período de entreguerras aparece esbozada en Benjamin, W., "El autor como productor", en: Iluminaciones III. Tentativas sobre Brecht, Madrid: Taurus, 1998, pp. 115-134. Esta conferencia desarrolla de manera programática la inseparabilidad de forma y contenido (o de cambio técnico y tendencia revolucionaria). El sostenimiento de los viejos autores consagrados en el nuevo contexto industrial no hace más que perpetuar el pasado como si los nuevos medios no lo resignificaran, como si fueran solo medios neutrales. 
tal como se argumentó previamente, deprecia el rol de la novedad técnica en la redefinición de lo político. En suma, la noción de copia benjaminiana articula una posición polivalente de lo técnico en la cual lo político excede los marcos de acción de las posiciones reseñadas por Feenberg, incluso aquellas que adjudica a la teoria crítica.

\subsection{La tensión materialismo-idealismo y el problema de la neutralidad de las técnicas}

Consideremos otra clasificación del pensamiento de Benjamin en relación con la copia reproductible ¿Qué significa exactamente ser un "materialista" a la hora de analizar un medio técnico? Esa es una de las preguntas que subyace a la crítica de Hennion y Latour a Benjamin y que se intentará aclarar en el marco de esta sección. Hennion y Latour afirman que un materialista genuino debería considerar que el rol de la técnica en el arte es el de un "productor activo", no el de un agente que pervierte demoníacamente su estatuto ${ }^{40}$. Pero Benjamin explora precisamente esta posibilidad cuando piensa cómo la frontera convencional burguesa de arte se verá conmovida por el poder transformador de ciertos nuevos medios técnicos, algo que se anticipa desde el epígrafe de Valéry que abre el ensayo sobre el cambio de función del arte: "De la placa fotográfica es posible hacer un sinnúmero de impresiones; no tiene sentido preguntar cuál de ellas es la impresión auténtica. Cuando llega el instante en el que el criterio de autenticidad falla ante la producción artística, es cuando la función social del arte en su conjunto se ha trastornado también. En lugar de su fundamentación en el ritual, debe aparecer su fundamentación en otra praxis, a saber, su fundamentación en la politica" ${ }^{41}$.

Si seguimos esta idea podríamos en principio afirmar que, en este sentido amplio, Benjamin es efectivamente materialista si consideramos el tipo de objetos que toma para su investigación (daguerrotipos, litografias, fotografia, montaje cinematográfico, mecanismos de reproducción material, etcétera.). En este sentido es tan materialista como Marx cuando explora en El capital la lógica de las máquinas bajo el modo de producción industrial y se sumerge en su modo (material) de existencia con el objetivo de contrastarlo con el de

\footnotetext{
${ }^{40} C f$. Hennion, A. y B. Latour, "How to make mistakes on so many things at once -and become famous for this", p. 95.

${ }^{41}$ Benjamin, W., "La obra de arte en la época de su reproductibilidad técnica", pp. 34-35.
} 
las herramientas ${ }^{42}$. Allí, Marx analiza el nuevo tipo de obrero que impone esta máquina-herramienta por su propio despliegue: un obrero-apéndice limitado a seguir las operaciones de las máquinas y a "colaborar" con ella en los momentos en que el proceso productivo lo requiere, rol similar al que Benjamin adjudica al fotógrafo cuando aparece la instantánea en "Breve historia de la fotografia" y se abandonan los procedimientos artesanales previos que, en sus orígenes, como ya señalamos, producían objetos únicos.

En el ensayo sobre la obra de arte, Benjamin comparte el interés de Marx por aquello que el medio técnico ofrece de manera inmanente, independientemente de sus usos potenciales o virtuales. Esto sucede, por ejemplo, cuando valora el potencial emancipatorio del cine como medio material que implica -por su propia naturaleza- una cierta configuración de la relación obra-auditorio, una cierta gramática de producción (a partir del montaje), un principio de iteración que permanece intacto frente a las peripecias de cada film en particular, un mecanismo de desauratización basado en la imposibilidad de un "original" en las obras de la reproductibilidad técnica (es decir cinematográficas y fonográficas), entre otros rasgos inmanentes. Pero al mismo tiempo, en el procedimiento del montaje de fotogramas, Benjamin detecta un rasgo novedoso de la reproductibilidad técnica analógica del siglo XX: su "capacidad de mejora": "El cine es asi la obra de arte con mayor capacidad de ser mejorada. Y esta capacidad suya está en conexión con su renuncia radical a perseguir un valor eterno" ${ }^{43}$. Este cambio de orden técnico contrasta con el estado de clausura que rige para las producciones auráticas: en tanto no hay original, solo existen versiones posibles ${ }^{44}$. De tal modo, la preocupación que comparten Marx y Benjamin, más allá de su circunstancia histórica, no es solo qué implicaciones o impactos sociales tienen estos nuevos modos materiales de producción (y reproducción, en el caso de Benjamin), sino, especialmente,

${ }^{42}$ Cf. Marx, K., El Capital, v. I, Buenos Aires: Siglo XXI, 2010, especialmente los Capítulos 12 y 13.

${ }_{43}$ Benjamin, W., "La obra de arte en la época de su reproductibilidad técnica", p. 41.

${ }^{44}$ En relación con esto, algunos autores ven una similitud entre cine y programación por la manipulación lineal (en el tiempo homogéneo de la reproducción técnica) de estados discretos, sean estos bits o fotogramas. La novedad más relevante de este aspecto para una teoría de la copia es la imposibilidad de "clausura" en las obras de la reproductibilidad técnica, donde no solo no hay original, sino que además la existencia de una obra solo puede considerarse a partir de la suma de sus versiones, como lo ilustra el caso paradigmático de la Metropolis de Lang. Para una discusión en extenso sobre la "capacidad de mejora" y la existencia de múltiples montajes de una misma obra, $c f$. Berti, A., "Fotogramas autorizados: La crisis de la noción de obra cinematográfica ante las remasterizaciones", 2018. 
qué nuevas configuraciones o gramáticas de producción novedosas se abren una vez que se introducen ciertos medios técnicos innovadores.

Una de las críticas de Hennion y Latour tiene que ver precisamente con este último aspecto. Benjamin, argumentan estos dos críticos, pretende recuperar un estatuto activo para la técnica como si no lo hubiera tenido en verdad desde siempre. Contra los idealistas, Benjamin pone en primer plano los medios técnicos de reproducción y su importancia para las obras que producen. Pero, para ellos, Benjamin sigue siendo idealista en tanto no otorga un rol positivo a la presencia material de los soportes ni a la repetición técnica que se despliega antes de las técnicas de fines de siglo XIX que estudia y presenta como rupturistas. La tesis de Hennion y Latour en este punto es que tal ruptura es una mera invención teórica tranquilizante: siempre hubo reproducción a través de medios técnicos; la reproducción es la base misma de toda práctica artística (y, podriamos agregar, de toda práctica cultural en sentido lato, tal como se indicó en la primera sección). Claro que la reproducción no tiene por qué involucrar los medios técnicos específicos de siglo XIX o XX. Cuando el pintor renacentista copia y reproduce modelos de la tradición lo hace a través de óleos, pinceles y otros andamiajes materiales. Estos últimos son condición necesaria de cualquier reproducción o proceso de copia o iteración. Un punto débil de este argumento es que no contempla la estandarización, automatización y discretización ${ }^{45}$ implicadas en la reproductibilidad técnica que Benjamin señala como distintivas, y de las que se derivan la aceleración y masificación que sustentan nuevas formas y prácticas politicas. Es decir, omiten el problema de la copia idéntica sin original señalando que siempre existieron copias de originales, a las que en periodos previos no se contemplaba como tales. Pero como ya lo señala Schwarzbock ${ }^{46}$, la intuición más potente de Benjamin es sobre la manera en que la aparición de la copia idéntica modifica especialmente el estatuto de lo no seriado.

Si esta interpretación es correcta, aquí se podría concebir un intento de defensa de Benjamin del siguiente modo. Es falso afirmar que la posición benjaminiana flirtea simultáneamente con el materialismo y el idealismo.

\footnotetext{
${ }^{45}$ Por discretización nos referimos a la codificación del continuo del mundo en unidades discretas, cuantificables, que permiten tratarlas de modo equivalente. Sea esta equivalencia la de las medidas de piezas que devienen intercambiable en la maquinaria industrial, o de las medidas de un fotograma y de las perforaciones en el rollo de film (lo que habilita, por ejemplo, las operaciones de montaje). A propósito de la discretización como particularidad del cine frente a las demás artes, véase Berti, A. "Fotogramas autorizados...", 2018.

${ }^{46}$ Schwarzböck, S., Los monstruos más frios: Estética después del cine, 2017.
} 
Benjamin es materialista pero está abocado a interpretar un fenómeno específico de reproducción. Es cierto, por una parte, que este fenómeno en términos generales es constitutivo de la práctica artística y en tal sentido existió siempre (la repetición, el proceso de copia técnicamente asistido). Pero también es cierto que este fenómeno adquiere dimensiones y alcances singulares a principios del siglo XX y este salto cualitativo lo distingue de otros procesos técnicos de épocas anteriores, por ejemplo, a los de la pintura o escultura clásicas. El punto débil de la crítica de Hennion y Latour es que no contempla el valor diferencial que Benjamin le otorga a la estandarización, automatización y discretización implicadas en la reproductibilidad técnica (claramente conectados con los procesos de aceleración y masificación). La polivalencia en clave politica que encontramos en Benjamin no puede leerse correctamente sin considerar estos aspectos técnicos materiales. De nuevo, en el ensayo de la obra de arte no se trata de elegir otras tecnologías, sino de explorar una de las valencias que porta el nuevo medio.

Aquí se abre otra esfera de cuestiones que no es menor. Pensemos en el siguiente contraste. La hipótesis de que la pintura o escultura es peligrosa si cae en manos de gobiernos fascistas resulta una suerte de exageración, en parte debido a la dimensión histórica involucrada: pintura y fascismo no tienen atados sus orígenes históricos, a diferencia del cine y el fascismo, y en parte debido a la dimensión comunicativa que comprenden. El medio técnico de la pintura está restringido espacialmente a los museos y centros de arte ${ }^{47}$. La intuición explicitada por Benjamin ${ }^{48}$ de que el cine (o ciertos medios de comunicación masivos) constituyen una amenaza crucial si llegan a ser tomados en manos fascistas no nos resulta extraña hoy en día ni tampoco resultó inverosímil en su momento histórico; de hecho, Adorno y Horkheimer retomaron este hilo argumentativo en 1944 en la Dialéctica de la ilustración. En este punto sí es conveniente retornar al propio Latour para ver concretamente cómo interpreta la relación entre fuerzas sociales, hechos sociales y entes materiales.

¿Cuál es la relación entre un régimen político-ideológico (por ejemplo, el fascismo europeo invocado por Benjamin) y el sistema de cultura material que este comprende? El materialismo latouriano afirmaria que no hay fascismo

47 Sin embargo, en un comentario crítico de dos congresos sobre las Artes realizados en París en 1935 y Venecia en 1936, Benjamin denuncia un intento del fascismo por sostener el valor cultual en Benjamin, W., "Segunda carta de París: Pintura y fotografia", en: Estética de la imagen, Buenos Aires: La Marca, 2015, pp. 133-135. Esto es, reafirmar el valor de la tradición en un contexto en el que su relación con el sistema de producción ya no existe. Esta lectura adelanta algunos aspectos del concepto de "estetización", es decir, hacer como si la técnica no modificara a las artes preexistentes, insistiendo en la neutralidad de tales medios técnicos.

48 Benjamin, W., "La obra de arte en la época de su reproductibilidad técnica", pp. 51-56. 
sin cinematografia y sin fotografia, pero tampoco lo hay sin arquitectura, sin folletos, y sin los miles de actos de reproducción técnicamente mediada que están plegados tras cada elemento de su cultura material. Es decir, es erróneo pensar que primero tenemos un cierto régimen politico inmaterial, descorporizado, y luego se lo legitima materialmente. Todo forma parte del mismo proceso. No tiene sentido distinguir entre la arquitectura y su "uso" para una ideología política, religiosa, etcétera., porque precisamente si una ideología existe, se mantiene viva, se institucionaliza, se hace hegemónica, es porque fácticamente ya está andamiada de manera material en la realidad (con iglesias, con monumentos, con esculturas, con grandes representaciones materiales, etcétera.). Entonces lo que plantea Latour es que no hay ambigüedad en las técnicas. A fin de cuentas, no tiene sentido la pregunta por la ambigüedad o la neutralidad de las técnicas; como bien lo resume el provocativo título de uno de sus artículos: "La tecnología es la sociedad hecha para que dure".

Y en este punto sí hay una diferencia relevante con Benjamin, porque en el caso del filósofo alemán la pregunta por los usos de las técnicas de reproductibilidad (que avalaría una cierta idea de neutralidad de la técnica) aparece en paralelo a la pregunta por los aspectos inmanentes de estos nuevos medios (por lo que insistimos en la idea de su polivalencia). A lo largo de todo el ensayo sobre la obra de arte vemos cómo Benjamin experimenta y describe la ambigüedad de un proceso innovador cuya dinámica todavía no está del todo clara precisamente por el hecho de que se trata de un fenómeno relativamente reciente, pero que modifica la percepción de lo preexistente. A finales del primer tercio del siglo XX en el ámbito germinal de tematización de la cultura de masas desde las humanidades todavía tiene sentido preguntarse cuán peligroso es que ciertos medios técnicos caigan en manos fascistas, o cuán esperanzador es que sean dirigidos por una visión comunista. Pero esta pregunta tiene sentido solo si consideramos que, además de que la tecnología es controlable, hay algún tipo de separación entre medios y fines, alguna clase de independencia que los pueda caracterizar.

Ahora bien, si esta última interpretación es correcta, entonces el problema de fondo que atraviesa al ensayo sobre la obra de arte no es -tal como sugieren Hennion y Latour- una tensión irresuelta entre materialismo e idealismo, sino más bien una tensión, también inconclusa, entre inmanencia y trascendencia. Esto significa que Benjamin no flirtea con materialismo e idealismo, sino que más bien coquetea con un enfoque inmanentista y un enfoque trascendentista al mismo tiempo. Y esto es verdaderamente problemático, y es lo que origina 
buena parte de los "errores" conceptuales que denuncian Hennion y Latour en su artículo.

Veamos más de cerca esta tensión entre dos tipos de caracterización de los medios técnicos materiales, una de orientación inmanentista y la otra que deposita su peso en un aspecto trascendente. Por un lado, si la esencia del medio técnico fuera genuinamente inmanente entonces la pregunta por sus usos no debería aparecer. No importa quién tenga a cargo el medio, porque el medio ya "decide" por nosotros un conjunto de cosas. La pregunta por el uso, en esta perspectiva, no resulta ni siquiera formulable, lo cual elimina (o al menos debilita) paralelamente el lenguaje del "peligro" y la "emancipación" que tanto protagonismo tiene dentro del ensayo benjaminiano. Por otro lado, si aquello que define al medio técnico es, en cambio, trascendente a él entonces la pregunta por el tipo de propiedades intrínsecas que trae una cierta innovación pasa a un segundo plano; no importa tanto como los usos que fácticamente se le den al nuevo medio en cuestión. Son esos usos particulares, en cierto modo contingentes y aleatorios, los que definen el perfil axiológico de un determinado artefacto o sistema técnico.

De lo anteriormente planteado se desprenden tres ideas. La primera es que las preguntas por los aspectos inmanentes y trascendentes de la técnica conforman una genuina oposición conceptual. En tal sentido si propusiéramos sostenerlas al mismo tiempo nos veríamos en problemas: no se puede invocar y eliminar en un mismo movimiento la pregunta por la neutralidad de las mediaciones técnicas. Y eso es lo que hace Benjamin repetidamente a lo largo de su ensayo ${ }^{49}$. La segunda intuición es que es razonable calificar a Benjamin de "materialista" en la medida en que está abocado a interpretar un fenómeno específico de reproducción propio del primer tercio de siglo XX: el de la copia analógica que por su carácter industrial es necesariamente seriada. En sí mismo el fenómeno de copia no es radicalmente nuevo, pero sí lo es este tipo particular de copia como para que llame la atención y demande indagación filosófica. La tercera idea que se ha tratado de explicitar es que lo fundamental del carácter polémico del escrito de la obra de arte no reside en la tensión materialismo/idealismo sino en la tensión más genérica y englobante de una

\footnotetext{
49 Efectivamente, dicha tensión podría ser leída dialécticamente en el sentido de Benjamin, es decir, como una tensión que no se resuelve al modo hegeliano sino que se mantiene (como en el pensamiento teológico-bíblico). Con todo, considerar los aportes de Benjamin a la filosofia de la técnica nos obligan a encontrar una solución, al menos parcial, a aquello que aparece como problemático en el marco propuesto.
} 
posición inmanentista y otra trascendente, donde acaso la idea de polivalencia permita recontextualizar la discusión atendiendo a la tensión entre inmanencia y trascendencia. En este trabajo hemos hablado de polivalencia para referirnos a la intuición de que cada cambio técnico entraña valores sin que eso implique asumir necesariamente una teleología determinista, y que precisamente tal apertura instaura sentidos politicos antes inexistentes o clausurados.

Ensayemos una alternativa a estas tensiones que permita pensar a Benjamin como filósofo de la técnica: su formulación de una teoría de la replicación. Solo desde el momento en que una organización artificial de la materia puede ser comprendida y reproducida por otro que no sea su creador original podríamos hablar de técnica, o, recuperando la conceptualización stiegleriana, de epifilogénesis (el nivel de organización específico de lo técnico y lo humano). La novedad que introduce Benjamin es identificar el modo epifilogenético del siglo XX, la reproductibilidad analógica, hija de la epifilogénesis del siglo XIX, la reproductibilidad fabril exteriorizada en la máquina. La homogeneidad que la máquina otorga al registro, la estandarización de los 24 cuadros por segundo en cinta de $35 \mathrm{~mm}$ que permite la operación de montaje y posteriormente el copiado en serie a nivel industrial ${ }^{50}$. Tal estandarización a su vez permite escalar y acelerar, dos fenómenos propios de la cultura de masas, de los que la reproductibilidad técnica es condición necesaria. Éste podría ser considerado el aspecto inmanente de la técnica en Benjamin, es decir, la nueva axiología política que establece: el de una política de masas.

\section{Conclusiones}

El presente trabajo ha intentado reivindicar la relevancia filosófica del problema de la reproducción técnica, más específicamente de la copia seriada, para el actual debate en filosofia de la técnica. En este contexto hemos explorado algunas intuiciones de orientación ontológica y política en la obra de Benjamin procurando evaluar su fortaleza en relación con las taxonomias axiológicas más extendidas en la actualidad. Una de las conclusiones que podemos desprender de este último aspecto es que la propuesta benjaminiana no se deja encasillar fácilmente en ninguna de las cuatro categorías ofrecidas por Feenberg. En su lugar nuestra propuesta fue interpretar a Benjamin en términos de sus

\footnotetext{
50 Bien que, como Benjamin señala, se mantiene abierto a la "capacidad de mejora", es decir a la multiplicación de versiones diferentes por la inexistencia de un original y la posibilidad de diferentes montajes.
} 
aportes a una teoría inmanentista de los medios artificiales que resulta, a su vez, compatible con la admisión de la polivalencia técnica. Asimismo, hemos procurado señalar la insuficiencia de las críticas de Hennion y Latour mediante la recontextualización de sus aportes en función de un corrimiento de la tensión idealismo-materialismo hacia la de inmanentismo-transcendentismo.

Entre los aspectos pendientes que deja esta tematización del problema de la reproductibilidad técnica y sus rasgos inmanentes hay uno especialmente importante relacionado con las posibilidades de avanzar en la construcción de una teoría de la copia (y sus limites): la desaparición del original supone el paso del producto al proceso. En tanto ya no hay obras conclusas definitivas (el original aurático), sino versiones que son, materialmente, inscripciones de objetos temporales en soportes estandarizados (el filmico), anticipan el modo técnico de existencia que cataliza hacia el final de la segunda guerra: el de los programas. Por ello, la teoría benjaminiana es una propuesta fértil para incorporar el problema de la copia en las discusiones de la filosofia de la técnica: un abordaje a la vez inmanente (la estandarización) y trascendente (los nuevos modos de política de masas que inaugura) de la técnica en Benjamin. Tal aproximación implica un intento de contemplar momentos de autonomía y momentos de instrumentalidad que fundan un modo particular de existencia técnica de las copias, el de entidades estandarizadas y relativamente estables, de alcance masivo, que anticipan el modo de ser de la técnica contemporánea.

Recibido: 29/04/2019

Aceptado: 04/07/2019

\section{Bibliografia}

Agamben, G., Infancia e historia: Destrucción de la experiencia y origen de la historia, Buenos Aires: Adriana Hidalgo, 2007.

Benjamin, W., "Breve historia de la fotografia", en: Estética de la imagen. Buenos Aires: La Marca, 2015, pp. 83-107.

Benjamin, W., "El autor como productor", en: Iluminaciones III. Tentativas sobre Brecht, Madrid: Taurus, 1998, pp. 115-134.

Benjamin, W., "La obra de arte en la época de su reproductibilidad técnica", en Estética de la imagen. Buenos Aires: La Marca, 2015, pp. 25-81.

Benjamin, W., "Réplica a Oscar A. H. Schimtz", en: Estética de la imagen. Buenos Aires: La Marca, 2015, pp. 147-150. 
Benjamin, W., "Segunda carta de París: Pintura y fotografia", en: Estética de la imagen. Buenos Aires: La Marca, 2015, pp. 125-135.

Benjamin, W., "Sobre algunos temas en Baudelaire", en: Iluminaciones II. Poesía y capitalismo, Madrid: Taurus, 1998.

Berti, A., "Fotogramas autorizados: La crisis de la noción de obra cinematográfica ante las remasterizaciones", en: del Rio Riande, G., G. Calarco y otros (eds.), Humanidades Digitales: Construcciones locales en contextos globales. Actas del Congreso Internacional de la Asociación Argentina de Humanidades Digitales. Buenos Aires: Editorial de la Facultad de Filosofia y Letras Universidad de Buenos Aires, 2018.

Bimber, B., "Tres caras del determinismo tecnológico", en: Smith, M. y L. Marx (eds.), Historia y determinismo tecnológico, Madrid: Alianza Editorial, pp. 95-116.

Boivin, N., Material Cultures, Material Minds. The Impact of Things on Human Thought, Society and Evolution, Nueva York: Cambridge University Press, 2008.

Bourdieu, P., Outline of a Theory of Practice, Cambridge: Cambridge University Press, 2013.

Crelier, A. y D. Parente, "La tecnicidad humana y animal en un marco naturalista. Problemas y perspectivas en el debate contemporáneo", en: Filosofia UIS, v. XIII, 2 (2014), pp. 17-36.

Cuevas, A., "Artefactualidad animal”, en: Ludus Vitalis, v. XXIV, 45 (2016), pp. 155-174.

Dawkins, R., El gen egoísta. Las bases biológicas de nuestra conducta, Barcelona: Salvat, 1993.

Feenberg, A., Questioning Technology, Londres: Routledge, 1999.

Harman, G., Hacia el realismo especulativo, Buenos Aires: Caja Negra, 2015.

Hennion, A. y B. Latour, "How to make mistakes on so many things at once-

and become famous for this", en: Gumbrecht, H.U. y M. Marrinan (eds.), Mapping Benjamin: The work of art in the digital age, Stanford: Stanford University Press, 2003, pp. 90-97.

Hodder, I., Entangled. An Archaeology of the Relationships between Humans and Things, Londres: Wiley-Blackwell, 2012. https://doi.org/10.1002/9781118241912

Holbraad, M. y M. Pedersen, The Ontological Turn. An Anthropological Exposition, Londres: Cambridge University Press, 2017. https://doi.org/10.1017/9781316218907

Latour, B., Reensamblar lo social. Una introducción a la teoría del actor-red, Buenos Aires: Manantial, 2005.

Leroi-Gourhan, A., El hombre y la materia. Evolución y técnica I, Madrid: Taurus, 1988.

Löwy, M., Walter Benjamin: aviso de incendio: Una lectura de las tesis "Sobre el concepto de historia”, Buenos Aires: FCE, 2002.

Marx, K., El Capital, v. I, Buenos Aires: Siglo XXI, 2010.

McLuhan, M. y E. McLuhan, Leyes de los medios. La nueva ciencia, México: Alianza, 1990.

McLuhan, M., Comprender los medios de comunicación. Las extensiones del ser humano, Barcelona: Paidós, 2009.

Ong, W., Oralidad y escritura: Tecnologías de la palabra, Ciudad de México: FCE, 1987. 
Parente, D., "Algunas precisiones sobre el determinismo tecnológico y la tecnología autónoma. Una lectura sobre la filosofia de Langdon Winner”, en: Redes, v. XII, 23 (2006).

Pinch, T. y W. Bijker, "The Social Construction of Facts and Artefacts: Or How the Sociology of Science and the Sociology of Technology Might Benefit Each Other", en: Social Studies of Science, v. XIV, 3 (1984), pp. 399-441. https://doi. org/ 10.1177/030631284014003004

Sandrone, D., "La especificidad del objeto industrial y la ontología de los objetos técnicos: acerca de los enfoques semánticos y sintácticos de la tecnologia”, en: Quadranti. Rivista internazionale di filosofia contemporanea. v. IV, 1-2 (2016), pp. 215-242.

Sandrone, D., Aportes para una nueva concepción del diseño tecnológico: Un estudio filosófico de su naturaleza y su rol en el cambio tecnológico, Tesis (Fil.), Córdoba: Universidad Nacional de Córdoba, 2016.

Schwarzböck, S., Los monstruos más frios: Estética después del cine, Buenos Aires: Mardulce, 2017.

Stiegler, B., La técnica y el tiempo I. El pecado de Epimeteo, Hondarribia: Editorial Hiru, 2002.

Wilson, E.O., Sociobiology, Cambridge: Belknap Press, 1975. 